\title{
FORMAÇÃO CONTINUADA EM PROJETOS E PROGRAMAS SOCIAIS ESPORTIVOS: UM ESTUDO DE CASO
}

\author{
CONTINUING EDUCATION IN SPORTS SOCIAL PROJECTS AND PROGRAMS: \\ A CASE STUDY
}

FORMACIÓN CONTINUA EN PROYECTOS Y PROGRAMAS SOCIALES

DEPORTIVOS: UN ESTUDIO DE CASO

Amauri Aparecido Bássoli de Oliveira*, Camila Rinaldi Bisconsini*, , Fabiane Castilho Teixeira*, Claudio Kravchychyn*, leda Parra Barbosa-Rinaldi*, Alberto Reinaldo Reppold Filho**

Palavras-chave Política social.

Educação continuada.

Esportes.

Cursos de

capacitação.

Keywords

Public Policy.

Education,

continuing.

Sports.

Training courses.

Palabras clave

Política social.

Educación continua.

Deportes.

Cursos de

capacitación.
Resumo: Esta pesquisa descritiva e documental objetivou analisar o processo de formação continuada do Programa Segundo Tempo, do Ministério do Esporte brasileiro. A coleta de dados consistiu na aplicação de questionários eletrônicos, respondidos por 23 coordenadores pedagógicos, 267 professores e 198 monitores de esportes de entidades convenentes, e na consulta a documentos internos da Secretaria Nacional de Esporte, Educação, Lazer e Inclusão Social. Sob o apontamento e a análise de aspectos positivos e negativos, verificou-se efetividade no processo de formação continuada, deflagrado na capacitação pedagógica e amparado pelo material didático disponibilizado aos recursos humanos atuantes no programa.

Abstract: This descriptive, documental research looks into the process of continuing education for the Brazilian Ministry of Sports' Program Segundo Tempo. Data collection consisted of applying electronic questionnaires to 23 pedagogical coordinators, 267 teachers, and 198 sports monitors from partner organizations as well as consulting internal documents of the National Office for Sports, Education, Leisure and Social Inclusion. By indicating and examining positive and negative aspects, it verified the effectiveness of the process of continuing education triggered by pedagogical training and supported by the teaching material offered to personnel working in the program.

Resumen: Este estudio descriptivo y documental tuvo como objetivo analizar el proceso de formación continua que ofrece el Programa Segundo Tempo del Ministerio de Deportes de Brasil. La recolección de datos consistió en cuestionarios electrónicos, respondidos por 23 coordinadores pedagógicos, 267 profesores y 198 monitores de deportes de entidades asociadas, y en la consulta a documentos internos de la Secretaría Nacional de Deportes, Educación, Recreación e Inclusión Social. Apuntando y analizando aspectos positivos y negativos, se constató la eficacia del proceso de formación continua, iniciado en la formación pedagógica y con el apoyo de materiales didácticos puestos a disposición de los recursos humanos que trabajan en el programa.
*Universidade Estadual de Maringá. Maringá, PR, Brasil.

E-mail: amauribassoli@gmail.com

** Universidade Federal do Rio Grande do Sul. Porto Alegre, RS, Brasil. E-mail: areppold@portoweb.com.br

Recebido em: 24-04-2015 Aprovado em: 13-05-2016 (c) (1) (8) Licence 


\section{INTRODUÇÃO}

No Brasil, a priorização de políticas sociais destinadas a crianças e jovens tem início na década de 1980, período de profunda crise econômica, marcado por muitas transformações sociais e políticas (FARAH, 2007). Como parte dessa priorização, observou-se um aumento de projetos sociais para esse público (ZALUAR, 1994). O esporte ganha força nesse cenário, mediante o seu reconhecimento legal como direito (BRASIL, 1988) e a oficialização do termo "esporte educacional" para aplicação no ensino formal e/ou fora dele (BRASIL, 1993; 1998). Desde então, esse termo passa a ser utilizado como: conceito teórico, marcadamente em oposição ao esporte de alto rendimento; vocábulo técnico da política pública, compondo leis, estudos e documentos oficiais; e tipo específico de intervenção pedagógica, com missão de repensar as formas tradicionais de ensino-aprendizagem e contribuir para os processos de transformação social, por meio dos valores arraigados no esporte (GONZÁLEZ et al., 2014).

Nos projetos sociais para crianças e jovens, a prática esportiva passou, gradativamente, de ação complementar à formação para iniciação ao trabalho, nos anos 1980 (ZALUAR, 1994), a eixo norteador na década seguinte, originando os projetos e programas sociais esportivos (PPSE) ${ }^{1}$ (KRAVCHYCHYN, 2014), transformação alavancada por investimentos governamentais diretos e incentivos fiscais oriundos de leis infraconstitucionais (BRASIL, 1993; 1998).

Tal centralidade aproximou o esporte educacional dos PPSE. Promovidas por entidades públicas e privadas sem fins lucrativos, como institutos e organizações não governamentais (ONGs), essas iniciativas vêm se multiplicando nas últimas três décadas no Brasil (MELO, 2008; SILVEIRA, 2013), e ganhando relevância por seu potencial de formação, inclusão social e promoção da saúde (MELLO; FERREIRA NETO; VOTRE, 2009).

Na última década, o tema vem atraindo a atenção de pesquisadores da Educação Física e áreas afins, que contemplam temáticas dominantes, exemplificadas pelos trabalhos de Correia (2008), Vianna e Lovisolo (2009) e Souza et al. (2010), sobre a gestão de projetos/ programas; Lazzari, Thomassim e Stigger (2010), Monteiro (2010) e Hirama e Montagner (2012), direcionados aos aspectos socioeducativos; e Machado et al. (2011), Rodrigues, Darido e Paes (2013) e Souza et al. (2013), que abordaram aspectos pedagógicos.

No entanto, a expansão dos PPSE no Brasil e o interesse científico decorrente não influenciaram proporcionalmente a oferta de disciplinas e estágios curriculares nos cursos de formação inicial em Educação Física (SOUZA et al., 2011; ALVES; CHAVES; GONTIJO, 2012; ARAÚJO et al., 2012), constatação que sugere a necessidade da oferta de capacitação profissional e formação continuada nessas iniciativas.

Nessa perspectiva, este estudo aborda a proposta pedagógica do Programa Segundo Tempo (PST)2, do Ministério do Esporte (ME), estruturada em um processo de formação continuada referenciado por um material didático próprio e pela capacitação pedagógica (Figura 1).

10 termo "sociais esportivos" foi utilizado nesta pesquisa por ser o mais utilizado na literatura sobre projetos e programas sociais que elegem o esporte como eixo norteador. Conceitualmente, verifica-se similaridade a diversas denominações, tais como projetos/programas: socioeducacionais mediante o esporte (VIANNA; LOVISOLO, 2009), socioeducativos por meio do esporte (SOUZA et al., 2010) e socioesportivos (TUBINO, 2010). Em todas as publicações consultadas, tais iniciativas contemplam a faixa etária que compreende as fases da infância e juventude. Portanto, doravante, a utilização do termo trará implícita a faixa etária atendida.

2 Política pública do governo federal que prevê, mediante convênios com prefeituras municipais, governos estaduais e órgãos públicos ligados às três esferas governamentais, a descentralização de recursos para implantação de núcleos de esporte educacional em todas as regiões do País (BRASIL, 2015b). O PST tem por objetivo geral "democratizar o acesso ao esporte educacional de qualidade, como forma de inclusão social de crianças e jovens em situação de vulnerabilidade social" (BRASIL, 2015b, p. 6). 
Figura 1 - Estruturação da formação continuada do PST

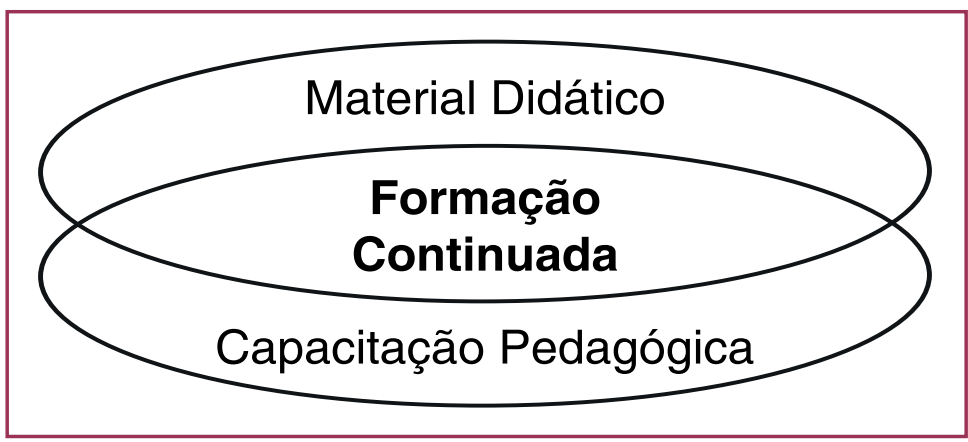

Fonte: adaptado de BRASIL (2015a, p. 8).

Face ao exposto, esta pesquisa objetivou analisar o processo de formação continuada do PST, considerando o material didático e a capacitação pedagógica como elementos fundamentais.

\section{MÉTODO}

De acordo com Yin (2015), este estudo de caso configura-se como uma investigação empírica que analisa um fenômeno contemporâneo (o caso do PST), em profundidade e em seu contexto (PPSE), beneficiando-se do desenvolvimento anterior das proposições teóricas para orientar a coleta e a análise de dados.

Do tipo descritivo e documental, o estudo utilizou como fontes de pesquisa: a) questionários compostos por questões abertas e fechadas, aplicados aos coordenadores, professores e monitores de entidades convenentes com o ME (convênios) vigentes; b) documentos da Secretaria Nacional de Esporte, Educação, Lazer e Inclusão Social (SNELIS) ${ }^{3}$, disponibilizados no Sistema de Acompanhamento Pedagógico e Administrativo (SIAPA)4.

Para verificar a clareza, objetividade e a adequação do instrumento ao objetivo da pesquisa, os questionários foram testados e aprovados em situação real junto aos recursos humanos $(\mathrm{RH})$ de dois convênios do PST.

A seleção de convênios e sujeitos participantes baseou-se em critérios de inclusão. Para convênios: a) ter efetivado pelo menos três renovações junto ao $\mathrm{ME}^{5 ;}$; b) estar vigente; c) aceitar participar. Para participantes (atuantes nesses convênios): a) ter participado de pelo menos uma capacitação pedagógica do PST; b) ser profissional (coordenador pedagógico ${ }^{6}$ ou professor $^{7}$ ) ou estudante (monitor $\left.{ }^{8}\right)$ de Educação Física; c) aceitar participar.

\footnotetext{
3 Órgão do ME responsável pela gestão do PST.

4 Base de dados da SNELIS que abriga toda a documentação relativa aos projetos pedagógicos, ao acompanhamento e à avaliação dos convênios. Disponível em: http://snelis-me.com.br/portal/pt-BR/.

5 Comprovada experiência no desenvolvimento do programa e, portanto, plena compreensão da proposta pedagógica do PST. O período de vigência de um convênio apresenta variações desde 2005, quando passou a ser publicado nas diretrizes do PST: 12 meses (BRASIL, 2005; 2007); de 12 a 24 meses (BRASIL, 2008); de 15 a 24 meses (BRASIL, 2009; 2010); de 15 a 26 meses (BRASIL, 2011; 2012; 2013); e de 24 meses (2014; 2015b).

6 Profissional de nível superior da área de Educação Física ou Esporte, com experiência pedagógica para coordenação, supervisão e orientação na elaboração de propostas pedagógicas (BRASIL, 2015b).

7 Até as Diretrizes de 2011 (BRASIL, 2011), o profissional de Educação Física ou esporte atuante nos núcleos do PST era denominado "coordenador de núcleo". Além de coordenar as atividades, esse profissional tinha a função de ministrar aulas, com o auxílio do monitor. A fim de sanar interpretações errôneas sobre a função, a denominação muda para "profissional de Educação Física", a partir das diretrizes do ano seguinte (BRASIL, 2012). Neste estudo, ao nos referirmos a esse profissional, utilizaremos o termo "professor", corroborando a constatação de Kravchychyn (2014), de que o termo foi utilizado para definir o profissional de Educação Física atuante nos PPSE brasileiros em todos os artigos científicos publicados sobre o tema, entre 2004 e 2013.

8 Estudantes de graduação regularmente matriculados em cursos de Educação Física ou Esporte que já tenham, preferencialmente, cursado
} 
Foram selecionados 27 convênios, de todas as regiões do País. Mensagens de e-mail foram enviadas a 1.143 participantes potenciais (vinculados aos convênios), explicitando objetivo, detalhamentos da pesquisa e contatos dos pesquisadores, juntamente com um link de acesso ao questionário específico, disponibilizado no aplicativo Google Docs durante 40 dias. Aceitaram participar da pesquisa: 23 coordenadores pedagógicos ( $85,2 \%$ do total dos envios), 267 professores (47,8\%) e 198 monitores (35,5\%). Os participantes concordaram com o Termo de Consentimento Livre e Esclarecido (TCLE).

A pesquisa foi desenvolvida sob uma abordagem prioritariamente qualitativa, apoiada por dados quantitativos. Os dados quantitativos foram tratados mediante estatística descritiva, com o auxílio do software SPSS (Statistical Package for Social Sciences), e apresentados por meio de frequência $(F)$ e porcentagem (\%) em tabelas, quais sejam: 1 e 5, organizadas a partir das respostas das questões fechadas, nas quais houve a assinalação de apenas uma alternativa; 2,3 e 4, a partir das respostas das questões abertas, categorizadas por associação de termos, segundo as indicações de Bardin (1977).

A consulta aos documentos internos (regulamentos e relatórios) foi devidamente autorizada pela gestão da SNELIS/ME.

Esta pesquisa integra o projeto "Análise da política pública relacionada ao esporte educacional: o caso do Programa Segundo Tempo - proposta pedagógica e formação dos recursos humanos", viabilizado por meio da Chamada ME/CNPq n 091/2013, e aprovado pelo Comitê de Ética em Pesquisas da Universidade Estadual de Maringá (parecer 692.014/2014).

\section{ESTRUTURA PEDAGÓGICA DO PST}

Como esclarecimento, este tópico apresenta o processo formativo do programa em análise, visto que a estrutura organizada e desenvolvida se coloca como objeto desta pesquisa.

Para o desenvolvimento de núcleos de esporte educacional ${ }^{9}$ do PST, os convênios recebem recursos financeiros para a contratação de $\mathrm{RH}$. Além dos coordenadores pedagógicos, professores e monitores dos convênios, o ME conta com o apoio de uma Equipe Pedagógica (EP), responsável pela estruturação e desenvolvimento do processo formativo, e da rede de Equipes Colaboradoras $(E C s)^{10}$, composta por docentes universitários e pós-graduandos de 44 Instituições de Ensino Superior (IES) parceiras, de todas as regiões do País. As ECs desenvolvem como principais ações junto aos convênios: orientação de projetos pedagógicos, cursos de capacitação, assessoria ao planejamento de atividades, visitas de acompanhamento e avaliação do processo (OLIVEIRA; KRAVCHYCHYN, 2011; RODRIGUES et al., 2012).

EP e ECs se responsabilizam diretamente pela elaboração do material didático do PST, que vem sendo construído a partir da base teórica da proposta ${ }^{11}$ desde 2008 . São 20 obras

o correspondente à primeira metade do curso (BRASIL, 2015b).

9 Para os quais doravante utilizaremos apenas a denominação "núcleos do PST".

10 O número de ECs - atualmente 19 - se altera de acordo com a demanda regional de convênios estabelecidos. Em média, cada membro de EC assessora 25 núcleos e seus RH (BRASIL, 2015a). 
(total: 125.200 exemplares) ${ }^{12}$ até o momento, todas impressas e disponibilizadas integralmente no formato digital, para download ${ }^{13}$ (Figura 2).

Figura 2 - Produção bibliográfica do PST a partir de 2008

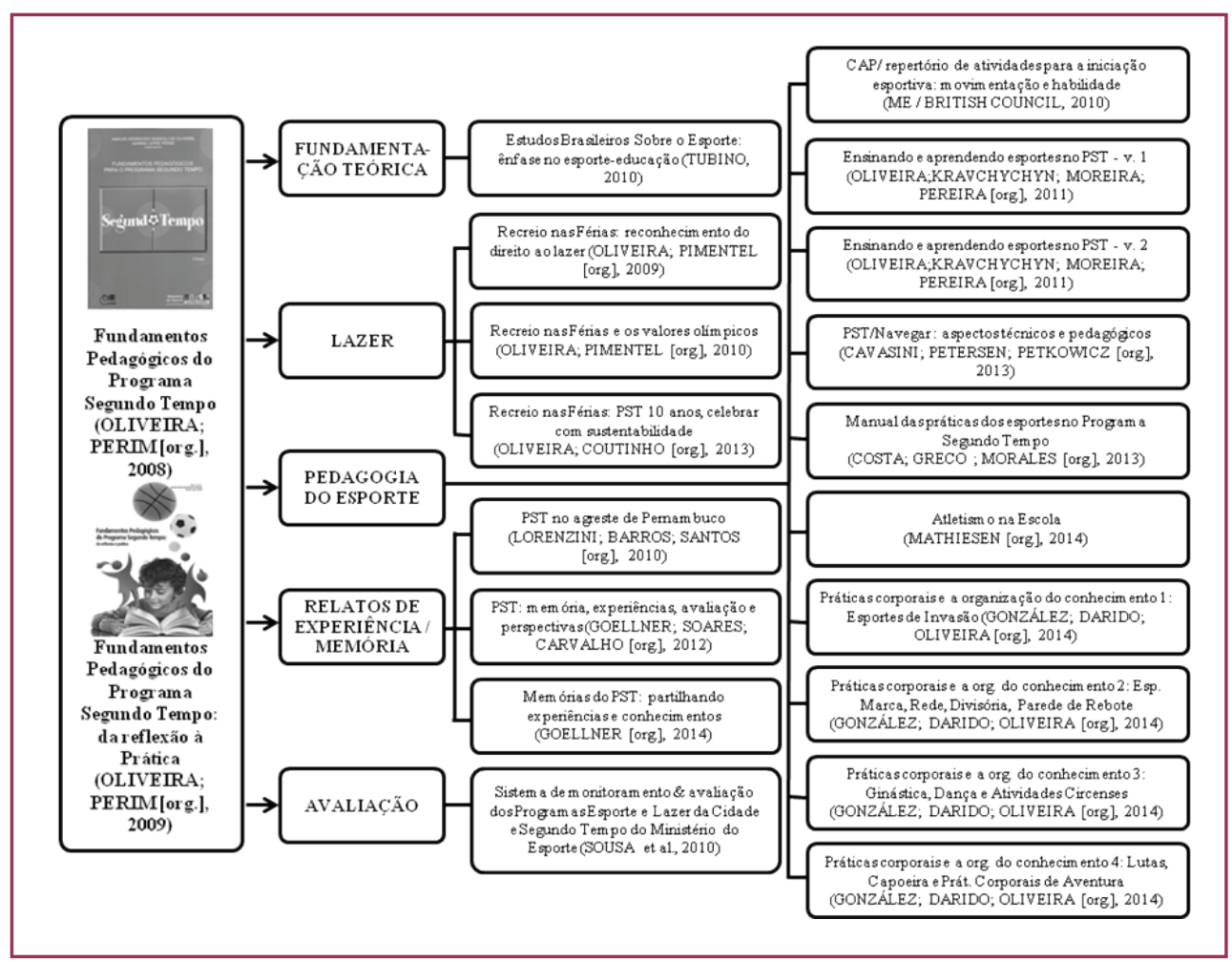

Fonte: Kravchychyn (2014, p. 98).

O material apresentado - com destaque aos dez livros didáticos, acima relacionados ao item "pedagogia do esporte" - subsidia o desenvolvimento pedagógico do PST (Figura 3).

Figura 3 - Processo de desenvolvimento pedagógico do PST

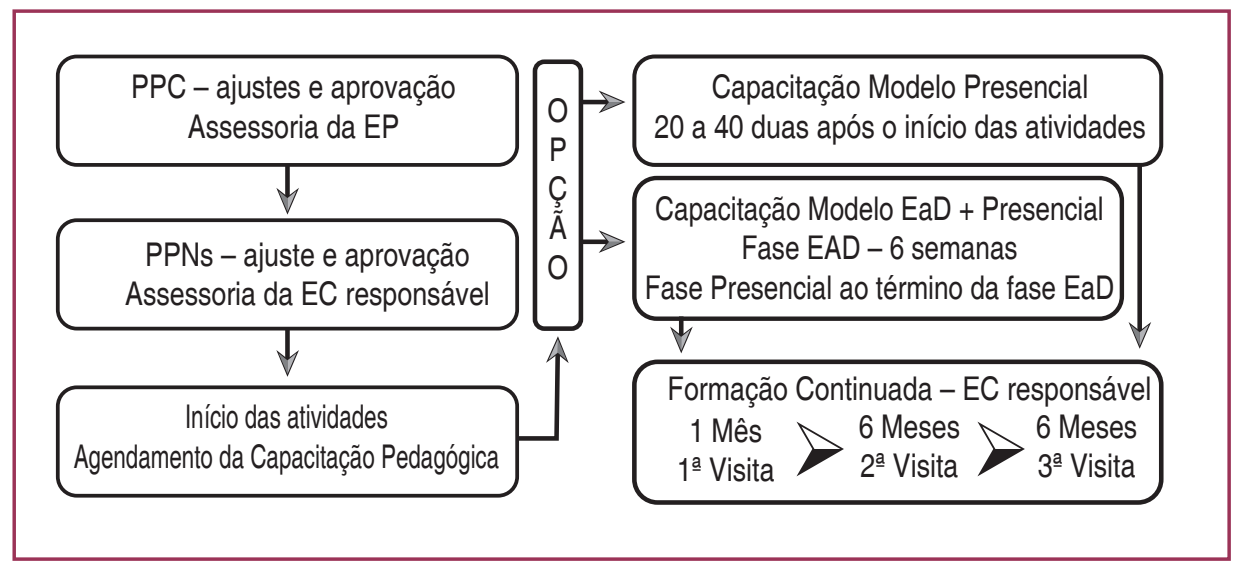

Fonte: adaptado de BRASIL (2015a, p. 3).

A aprovação do Planejamento Pedagógico de Convênio (PPC)14 é pré-requisito para o início das atividades. Assim que o PPC é cadastrado, um membro da

\footnotetext{
12 Fonte: Coordenação Geral de Desenvolvimento Pedagógico (CGDEP) da SNELIS/ME.

13 Disponível em: http://www.ufrgs.br/ceme/pst/site/publicacoes/livros.

14 Componentes do PPC: identificação; fundamentação teórica; diagnóstico; objetivos; conteúdos; estratégias metodológicas; processos avaliativos; recursos materiais; estrutura física; grades horárias dos núcleos; cronograma de atividades.
} 
EP passa a apoiar o coordenador pedagógico do convênio em sua construção, corrigindo e orientando os ajustes necessários até a aprovação do documento (BRASIL, 2015a).

O PPC baliza os Planejamentos Pedagógicos de Núcleo (PPNs), respeitando as especificidades culturais e de infraestrutura de cada comunidade atendida. $O$ coordenador pedagógico, principal elo entre convênio e $E C$, exerce papel relevante na organização pedagógica dos convênios (RODRIGUES et al., 2012; KRAVCHYCHYN, 2014).

No início das atividades ocorre a capacitação pedagógica do convênio, ministrada pela EC que assessora seu desenvolvimento, objetivando proporcionar conhecimentos e vivências baseados nos fundamentos e diretrizes do programa aos profissionais e monitores (RODRIGUES et al., 2012). Na capacitação, oferecida nas modalidades "presencial" ou "ensino a distância (EaD) + presencial", são desenvolvidos nove temas (Quadro 1).

Quadro 1 - Temas desenvolvidos na capacitação pedagógica

\begin{tabular}{|l|l|}
\hline Tema 1 & $\begin{array}{l}\text { Fundamentos do PST: entrelaçamentos do esporte, do desenvolvimento humano, da cultura e da } \\
\text { educação }\end{array}$ \\
\hline Tema 2 & Fundamentos do Lazer e da Animação Cultural \\
\hline Tema 3 & Corpo, gênero e sexualidade: educando para a diversidade \\
\hline Tema 4 & Desenvolvimento e Aprendizagem Motora: aspectos relacionados à prática \\
\hline Tema 5 & Questões da deficiência e as ações do PST \\
\hline Tema 6 & Organização e Desenvolvimento Pedagógico do PST \\
\hline Tema 7 & Procedimentos Metodológicos para o PST \\
\hline Tema 8 & Planejamento do PST: a intenção é compartilhar conhecimentos, saberes e mudar o jogo \\
\hline Tema 9 & Atividades Práticas \\
\hline
\end{tabular}

Fonte: adaptado de Oliveira; Perim (2009).

As capacitações presenciais duram dois dias, na própria cidade ou região dos convênios ${ }^{15}$. No caso de convênios menores (até 20 núcleos), os monitores são incluídos na formação. Em convênios maiores, os professores capacitados devem multiplicar o conhecimento, utilizando o material pedagógico oferecido pelo $\mathrm{ME}^{16}$, sob a assessoria da EC.

A modalidade $\mathrm{EaD}+$ presencial foi implantada em 2013. Consiste no trabalho de seis dos oito temas teóricos $(1,4,5,6,7$ e 8) trabalhados na fase EaD, como pré-requisito para inscrição do professor na fase presencial, que acontece em dois dias, preconizando atividades práticas (tema 9, com tarefas previamente atribuídas pela tutoria da $\mathrm{EC}$ na fase $\mathrm{EaD}$ ), troca de experiências e planejamento de atividades. Dois temas (2 e 3) são trabalhados na sequência, desencadeando 0 processo de formação continuada. Tal modalidade pode ser considerada um avanço, por oferecer maior aporte teórico prévio, enfatizar a prática pedagógica e instrumentalizar os RH para o trabalho com a ferramenta do EaD. Contudo, existe a limitação de acesso à internet em algumas localidades, que recebem a capacitação no modelo presencial (BRASIL, 2015a).

O cumprimento da etapa de capacitação deflagra automaticamente a formação continuada do programa, em ações a distância (com apoio do SIAPA) e presenciais (visitas semestrais de avaliação e assessoria).

15 No caso de dois ou mais convênios de menor porte, são realizadas capacitações regionais, respeitando os critérios de melhor estrutura e de proximidade de deslocamento. 


\section{RESULTADOS E DISCUSSÃO}

Os resultados a seguir apresentam a perspectiva de coordenadores pedagógicos, professores e monitores sobre o processo-alvo deste estudo e os elementos que o alicerçam. Conforme demonstra a Figura 2, tais elementos são delineados na obra organizada por Oliveira e Perim (2009), Fundamentos Pedagógicos do Programa Segundo Tempo, especialmente nos capítulos de autoria de Filgueira, Oliveira e Perim (2009) e Oliveira et al. (2009). Os referidos autores oferecem contribuições à discussão a seguir, assim como outros que pesquisaram 0 desenvolvimento da proposta, tais como Araújo et al. (2012), Starepravo et al. (2012), Rodrigues et al. (2012), Teixeira (2012) e Kravchychyn (2014), e também Diretrizes do PST (BRASIL, 2011; 2015a), que contemplam elementos pedagógicos.

\subsection{Formação continuada}

O conceito de formação/educação continuada é heterogêneo, um "guarda-chuva" que, segundo Gatti (2008, p. 57), comporta "[...] tudo que possa oferecer ocasião de informação, reflexão, discussão e trocas que favoreçam o aprimoramento profissional, em qualquer de seus ângulos, em qualquer situação".

Portanto, ações como cursos, congressos, seminários, palestras e reuniões pedagógicas (presenciais, em vídeo ou teleconferências) são passíveis de serem consideradas de formação ou educação continuada, desde que organizadas e estruturadas para um determinado aprimoramento profissional (GATTI, 2008), devendo levar em conta as necessidades dos professores e promover condições para o cumprimento efetivo das funções de ensinar e formar cidadãos (GASQUE; COSTA, 2003; ALTENFELDER, 2005). Nesse sentido, centrar as ações nas necessidades e anseios dos profissionais atuantes em PPSE é fundamental ao processo formativo nesse contexto.

No PST, a formação continuada é realizada em dois níveis: no acompanhamento e na assessoria das ECs e nas ações internas decorrentes, ambas centralizadas no coordenador pedagógico do convênio (KRAVCHYCHYN, 2014).

Embora haja contato direto das ECs com os monitores durante as visitas de avaliação in loco aos núcleos do PST, as ações a distância (plantões de atendimento, contatos telefônicos e online), fundamentais ao desenvolvimento pedagógico do programa (FILGUEIRA; OLIVEIRA; PERIM, 2009), dependem da intermediação dos coordenadores pedagógicos (principalmente) e dos professores. Diante disso, optamos pela apresentação da primeira questão somente a esses dois grupos (Tabela 1).

Tabela 1 - Efetividade da formação continuada da EC aos convênios.

\begin{tabular}{lcccc}
\hline \multirow{2}{*}{ Respostas } & \multicolumn{2}{c}{ CP } & \multicolumn{2}{c}{$\mathbf{P}$} \\
\cline { 2 - 5 } & $F$ & $\%$ & $F$ & $\%$ \\
\hline Sempre supre as necessidades pedagógicas & 12 & 52,2 & 110 & 41,2 \\
Quase sempre supre as necessidades pedagógicas & 8 & 34,8 & 94 & 35,2 \\
Raramente supre as necessidades pedagógicas & 2 & 8,7 & 55 & 20,6 \\
Nunca supre as necessidades pedagógicas & 1 & 4,3 & 8 & 3,0 \\
\hline Total & 23 & 100 & 267 & 100 \\
\hline
\end{tabular}

CP - Coordenadores Pedagógicos; P - Professores 
A formação continuada sempre (52,2\%) ou quase sempre (34,8\%) supreasnecessidades pedagógicas da maioria dos coordenadores, havendo indicações de que raramente $(8,7 \%)$ ou nunca $(4,3 \%)$ são supridas tais necessidades. Entre os professores também há predomínio de posicionamentos positivos (sempre: $41,2 \%$; quase sempre: $35,2 \%$ ); todavia, maior descontentamento (raramente: 20,6\%; nunca: $3 \%$ ) em relação aos coordenadores.

Os contatos das ECs direcionam-se mais frequentemente aos coordenadores pedagógicos. Todavia, verifica-se a necessidade de maior aproximação aos professores. A ferramenta $\mathrm{EaD}$, em franco desenvolvimento no programa, pode ser útil nessa tarefa.

A intenção desse suprimento é possibilitar que, mesmo apoiados por diretrizes estabelecidas, os professores tenham autonomia pedagógica diante da diversidade social e cultural do País (OLIVEIRA et al., 2009). Segundo Silva e Araújo (2005), a formação continuada deve incentivar a apropriação dos saberes rumo à autonomia, considerando os saberes derivados da experiência. Oliveira et al. (2009) reiteram essa afirmativa, ao recomendar aos professores do programa: "[...] ao planejar, você pode articular elementos de ações pedagógicas e criar situações dinamizadoras e de experimentação das diversas possibilidades de intervir metodologicamente" (p. 241).

Diante disso, a formação continuada ora tratada apresenta um segundo formato, coordenado e desenvolvido internamente e que contempla as especificidades, mas que conserva a orientação pedagógica do PST e a assessoria das ECs. Consultamos os participantes sobre as estratégias mais eficazes utilizadas nessas ações internas (Tabela 2).

Tabela 2 - Estratégias mais eficazes utilizadas pelos convênios na formação continuada interna.

\begin{tabular}{lccccccc}
\hline \multirow{2}{*}{ Respostas } & \multicolumn{3}{c}{$\mathbf{C P}$} & \multicolumn{3}{c}{$\mathbf{P}$} & \multicolumn{3}{c}{$\mathbf{M}$} \\
\cline { 2 - 8 } & $\boldsymbol{F}$ & $\%$ & $F$ & $\%$ & $F$ & $\%$ \\
\hline Reuniões pedagógicas & 15 & 65,2 & 162 & 60,7 & 120 & 60,6 \\
Palestras & 5 & 21,7 & 45 & 17,0 & 31 & 15,6 \\
Oficinas & 4 & 17,4 & 44 & 16,5 & 30 & 15,1 \\
Cursos & 1 & 4,3 & 31 & 11,6 & 26 & 13,1 \\
\hline
\end{tabular}

CP - Coordenadores Pedagógicos; P - Professores; M - Monitores

Fonte: dos autores.

As respostas demonstram a utilização de reuniões pedagógicas semanais ou quinzenais como estratégia mais eficaz (CP: 65,2\%; P: 60,7\%; M: 60,6\%), seguida de palestras (CP: 21,7\%; P: 17\%; M: 15,6\%), oficinas (CP: 17,4\%; P: 16,5\%; M: 15,1\%) e cursos (CP: 4,3\%; P: $11,6 \% ; M: 13,1 \%)$. A regularidade de reuniões pedagógicas permite o frequente diálogo entre os três grupos sobre o cotidiano dos núcleos. As discussões, reflexões e troca de experiências colocam-se como diferenciais na organização pedagógica e na eventual necessidade de redirecionamento das ações (OLIVEIRA et al., 2009).

Considerando a previsão de reuniões na rotina dos núcleos, o destaque dado às demais estratégias demonstra a apropriação da necessidade de construir uma práxis pedagógica direcionada às especificidades dos PPSE, previstas nas diretrizes do PST. Essa construção, alicerçada no trabalho das ECs, vem sendo objeto de estudos que evidenciam a gradativa assimilação e incorporação do processo de formação continuada pelos convênios, que parece influenciar positivamente a atuação profissional no contexto estudado (ARAÚJO et al., 2012; STAREPRAVO et al., 2012; TEIXEIRA, 2012). 
Dentro do processo formativo estudado, tem-se as capacitações pedagógicas do PST e o material didático que dá suporte à formação e atuação profissional no âmbito do programa. Os tópicos a seguir abordam, respectivamente, esses dois componentes, e sua influência e aplicação no dia a dia dos núcleos.

\subsection{Capacitação pedagógica}

Entre 2008 e 2014, o ME capacitou 17.448 profissionais de Educação Física para o trabalho em convênios do PST17. Trata-se de um processo em constante avaliação e revisão. Nesse item, a intenção foi a de analisar a relação entre os conteúdos da capacitação e 0 trabalho diário dos profissionais e monitores.

Foi solicitado aos participantes o apontamento de aspectos positivos e negativos sobre capacitação pedagógica. Os mais citados compõem, respectivamente, as Tabelas 3 e 4.

Tabela 3 - Principais aspectos positivos da capacitação pedagógica.

\begin{tabular}{lccccccc}
\hline \multirow{2}{*}{ Categorias } & \multicolumn{3}{c}{ CP } & \multicolumn{3}{c}{$\mathbf{P}$} & \multicolumn{3}{c}{$\mathbf{M}$} \\
\cline { 2 - 8 } & $F$ & $\%$ & $F$ & $\%$ & $F$ & $\%$ \\
\hline Relação entre teoria e prática & 20 & 87 & 158 & 59,2 & 91 & 46,0 \\
Integração dos participantes & 20 & 87 & 149 & 55,8 & 107 & 54,0 \\
Momentos de vivências práticas & 19 & 82,6 & 175 & 65,5 & 84 & 42,4 \\
Dinâmica utilizada para interação dos participantes & 18 & 78,3 & 150 & 56,2 & 68 & 34,3 \\
\hline
\end{tabular}

CP - Coordenadores Pedagógicos; P - Professores; M - Monitores

Fonte: dos autores.

Posicionamentos distintos são verificados nos três grupos quanto aos principais aspectos positivos da capacitação: os coordenadores pedagógicos destacam a relação teoriaprática e a integração dos participantes (87\% em ambos os itens); os professores, a importância das vivências práticas (65,5\%); e os monitores, a integração dos participantes (54\%).

Em pesquisa similar, Araújo et al. (2012), que abordaram a satisfação de participantes da capacitação pedagógica do PST nos Estados de Sergipe e Alagoas, também destacaram positivamente as vivências práticas e a troca de experiências com profissionais de outras frentes de trabalho.

Sobre a teoria trabalhada em capacitações pedagógicas do PST, Rodrigues et al. (2012) apresentam resultados satisfatórios quanto à apropriação dos conhecimentos teóricos veiculados. Segundo Krüger e Krug (2009), a relação teoria-prática permite construir a consciência profissional e refletir sobre a postura que se mantém diante dos fatos, mostrando a capacidade de autoavaliação e a percepção da coerência em relação ao processo educativo.

Ao longo dos anos, verifica-se que as mudanças no processo de capacitação promoveram avanços nessa direção, com maior tempo dedicado às práticas ${ }^{18}$, contemplando um importante aspecto identitário da comunidade da Educação Física. A presença do movimento permite dinamizar as reflexões e oportunizar experiências diversificadas.

17 Fonte: relatórios de gestão da Secretaria Nacional de Esporte Educacional/SNEED (2008-2010) e da SNELIS (2011-2014). Observação: 0 Decreto no 7.529/2011 promoveu a fusão entre a SNEED (então órgão gestor do PST) e a Secretaria Nacional de Desenvolvimento do Esporte e Lazer/SNDEL, dando origem à SNELIS.

18 Fonte: relatórios de gestão da Secretaria Nacional de Esporte Educacional/SNEED (2008-2010) e da SNELIS (2011-2014). 
Tabela 4 - Aspectos negativos da capacitação pedagógica.

\begin{tabular}{lcccccc}
\hline \multirow{2}{*}{ Respostas } & \multicolumn{2}{c}{$\mathbf{C P}$} & \multicolumn{2}{c}{$\mathbf{P}$} & \multicolumn{2}{c}{$\mathbf{M}$} \\
\cline { 2 - 7 } & $F$ & $\%$ & $F$ & $\%$ & $F$ & $\%$ \\
\hline Carga horária total & 11 & 47,8 & 72 & 28,1 & 2 & 1,0 \\
Aprofundamento dos conteúdos & 4 & 17,4 & 55 & 20,6 & 25 & 12,6 \\
Distribuição da carga horária por tema & 11 & 47,8 & 68 & 25,5 & - & - \\
Avaliação das ações & - & - & - & - & 66 & 33,3 \\
\hline
\end{tabular}

CP - Coordenadores Pedagógicos; P - Professores;; M - Monitores Fonte: dos autores.

Os aspectos negativos mais apontados pelos três grupos são: carga horária total e distribuição da carga horária por tema, destacadas pelos coordenadores pedagógicos (47,8\% para ambas); pouco aprofundamento dos conteúdos, ressaltado principalmente pelos professores (20,6\%); e avaliação das ações, apontada exclusivamente por parte do grupo de monitores (33,3\%), que não participou dessa etapa do evento ${ }^{19}$.

Os aspectos ressaltados são fundamentais ao processo reflexivo de construção dos modelos de capacitação. Conforme destacam Araújo et al. (2012, p. 55), é necessário que

[...] os saberes sistematizados no cotidiano dos núcleos sejam socializados entre os professores para, numa espécie de validação e construção coletiva [...] de um saber que é edificado pela prática, permitir a procura de referenciais teóricos que Ihes possibilitem o aprofundamento e diálogo reflexivo baseado não somente na experiência individual, por vezes limitada, mas, sobretudo, na discussão coletiva (grifo nosso).

A afirmativa supracitada e os dados ora apresentados reforçam a capacitação como ponto de ajuste teórico-metodológico, minimizando carências e deflagrando o processo de formação continuada. Obviamente, encontros de dois ou três dias não viabilizam aprofundamentos teóricos e vivências que contemplem plenamente o universo dos PPSE, suscitando a indicação da maioria dos pontos negativos apresentados.

No entanto, segundo os objetivos idealizados (BRASIL, 2015a), as capacitações devem nivelar o entendimento sobre os PPSE, suas exigências e especificidades, oferecendo uma visão ampliada dos fundamentos do PST. Intento que, considerando as respostas dos profissionais e monitores, parece ser cumprido nesse primeiro momento formativo.

Considerando a capacitação pedagógica e o material didático como elementos fundamentais à consolidação dos pressupostos teórico-metodológicos do programa, a utilização do material apresenta-se como fator essencial na aproximação desses pressupostos à ação pedagógica.

\subsection{Utilização do material didático}

Pretendeu-se analisar a aplicabilidade do material didático do PST, tendo como indicativo principal a frequência de sua utilização nas ações dos núcleos, para planejamento das atividades e consulta permanente (Tabela 5). 
Tabela 5 - Utilização do material didático do PST.

\begin{tabular}{lcccccc}
\hline \multirow{2}{*}{ Respostas } & \multicolumn{2}{c}{$\mathbf{C P}$} & \multicolumn{3}{c}{$\mathbf{P}$} & \multicolumn{2}{c}{$\mathbf{M}$} \\
\cline { 2 - 7 } & $F$ & $\%$ & $F$ & $\%$ & $F$ & $\%$ \\
\hline Sempre utiliza & 16 & 69,6 & 109 & 40,9 & 81 & 40,9 \\
Quase sempre utiliza & 7 & 30,4 & 94 & 35,2 & 104 & 52,5 \\
Raramente utiliza & - & - & 52 & 19,4 & 10 & 5,1 \\
Nunca utiliza & - & - & 12 & 4,5 & 3 & 1,5 \\
Total & 23 & 100 & 267 & 100 & 198 & 100 \\
\hline
\end{tabular}

CP - Coordenadores Pedagógicos; P - Professores; M - Monitores

Fonte: dos autores.

Verifica-se que os coordenadores pedagógicos utilizam o material disponibilizado sempre $(69,6 \%)$ ou quase sempre $(30,4 \%)$. Os professores mostram-se mais divididos, acusando o uso: sempre (40,9\%); quase sempre (35,2\%); raramente (19,4\%); e nunca $(4,5 \%)$. Já os monitores demonstram maior utilização em relação aos professores: sempre $(40,9 \%)$; quase sempre (52,5\%); raramente $(5,1 \%)$; e nunca $(1,5 \%)$.

A utilização efetiva do material didático do PST foi também investigada por Araújo et al. (2012). Na ocasião, 88,2\% dos professores investigados expressaram "[...] adesão ao leque de opções de atividades propostas, mesmo argumentando possibilidades de ressignificar as práticas a partir dos parâmetros colocados" (p. 49), algo previsto e até mesmo recomendado (OLIVEIRA et al., 2009).

Os dados apresentados reforçam a responsabilidade atribuída aos coordenadores pedagógicos e a consequente valorização dessa função no programa (RODRIGUES et al., 2012; TEIXEIRA, 2012; KRAVCHYCHYN, 2014).

Chama atenção o posicionamento de parcela significativa de professores que afirmam raramente ou nunca utilizar o material didático para consulta e planejamento $(23,4 \%$, na somatória). Tais dados corroboram a tendência, apresentada em outros estudos, de que parte dos profissionais de Educação Física privilegia as próprias experiências esportivas, em detrimento da incorporação de novas teorias e conhecimentos em seu fazer pedagógico (ROSÁRIO; DARIDO, 2005; MOREIRA, 2012).

Nota-se, contudo, predomínio absoluto na valorização e efetiva utilização do material didático entre os participantes do estudo.

\section{CONSIDERAÇÕES FINAIS}

Esta pesquisa abordou a formação de profissionais e estudantes de Educação Física para a atuação em PPSE, o que é exemplificado por uma política pública que prioriza essa ação desde o marco da construção de sua atual proposta pedagógica: o PST.

Foram apresentadas informações que evidenciam a efetividade e importância da formação continuada para os RH envolvidos, bem como da capacitação pedagógica e dos materiais didáticos, componentes fundamentais desse processo. Contudo, parte das respostas traz à tona alguns anseios dos participantes, que precisam ser considerados pela gestão do programa, podendo também referenciar outras experiências em PPSE. 
Como principal anseio destaca-se 0 atendimento a mais momentos de práticas pedagógicas nas capacitações presenciais. Mesmo havendo indicativos positivos nos relatórios da SNELIS, reforça-se a necessidade de atenção para este quesito.

O material didático, mesmo elogiado em sua concepção e estrutura, não teve plena utilização e consideração do suprimento das necessidades pedagógicas pelos participantes, fator que indica a necessidade de discussões aprofundadas e revisões apuradas sobre 0 material e sua aplicabilidade, o que nem sempre é possível em dois ou três dias. A utilização de parte da formação na modalidade EaD apresenta-se como um avanço nesse sentido.

Dessa forma, evidenciam-se problemas a serem enfrentados, mas, sobretudo, apresenta-se uma construção coletiva que vem sendo paulatinamente reconhecida pela comunidade científica e pelos profissionais de Educação Física que, partícipes da empreita, materializam a proposta junto aos beneficiados.

O saldo positivo observado na estrutura analisada reforça a ideia de que se deve valorizar o profissional em sua atuação, pois com isso se ganha em todos os sentidos. Ganha o profissional, que se sente valorizado; o beneficiado, que recebe um atendimento de melhor qualidade; e o programa, que se revigora e cumpre seu papel social.

Espera-se, portanto, que esta experiência do PST contribua com o planejamento e desenvolvimento de outros PPSE, visto que relata uma realidade nacional, apontando indicativos a serem refletidos em projetos e programas dessa natureza.

\section{REFERÊNCIAS}

ALTENFELDER, Anna Helena. Desafios e tendências em formação continuada. Construção Psicopedagógica, v. 13, n. 10, 2005. Disponível em: <http://pepsic.bvs-psi.org.br/scielo. php?script=sci arttext\&pid=S1415-69542005000100004\&lng=pt\&nrm=iso>. Acesso em: 3 ago. 2016.

ALVES, Heliana Castro; CHAVES, Aline Dessupoio; GONTIJO, Daniela Tavares. Uma andorinha só não faz verão: a integração do educador físico na rede de suporte social de crianças e adolescentes em situação de vulnerabilidade: discussões a partir de um curso de educação continuada. Pensar a Prática, v. 15, n. 2, p. 331-347, abr./jun. 2012.

ARAÚJJO, Allyson Carvalho et al. Formação e atuação pedagógica no Programa Segundo Tempo: reflexões sobre o fazer cotidiano do professor. Motrivivência, v. 24, n. 38, p. 40-58, jun. 2012.

BARDIN, Laurence. Análise de conteúdo. Lisboa: Edições 70, 1977.

BRASIL. Constituição da República Federativa do Brasil. Brasília: Senado Federal, 1988.

BRASIL. Diretrizes do Programa Segundo Tempo. Brasília: Ministério do Esporte, 2010.

BRASIL. Diretrizes do Programa Segundo Tempo. Brasília: Ministério do Esporte, 2011.

BRASIL. Estruturação e fluxo das ações da Coordenação Geral de Desenvolvimento Pedagógico (CGDEP) da Secretaria Nacional de Esporte, Educação, Lazer e Inclusão Social (SNELIS). Brasília: Ministério do Esporte, 2015a.

BRASIL. Lei no 8.672, de 06 de julho de 1993. Institui normas gerais sobre desportos, e dá outras providências. Brasília, 1993. Disponível em <http://www3.dataprev.gov.br/ sislex/ paginas/42/1993/8672.htm>. Acesso em: 3 ago. 2016.

BRASIL. Lei n. 9.515, de 24 de março de 1998. Institui normas gerais sobre desporto e dá outras providências. Presidência da República - Casa Civil. Disponível em: <http://www.planalto.gov.brl ccivil 03/leis//9615consol.htm>. Acesso em: 3 ago.2016. 
BRASIL. Manual de Orientações para a implantação de Núcleos do Programa Segundo Tempo. Brasília: Ministério do Esporte, 2005.

BRASIL. Programa Segundo Tempo: o esporte e a escola no mesmo time/diretrizes. Brasília: Ministério do Esporte, 2004.

BRASIL. Programa Segundo Tempo: ações de funcionamento dos núcleos. Brasília: Ministério do Esporte, 2007.

BRASIL. Programa Segundo Tempo: diretrizes 2012. Brasília: Ministério do Esporte, 2012.

BRASIL. Programa Segundo Tempo: diretrizes 2013. Brasília: Ministério do Esporte, 2013.

BRASIL. Programa Segundo Tempo: diretrizes 2014. Brasília: Ministério do Esporte, 2014.

BRASIL. Programa Segundo Tempo: diretrizes 2015. Brasília: Ministério do Esporte, 2015b.

BRASIL. Programa Segundo Tempo: diretrizes e orientações. Brasília: Ministério do Esporte, 2008.

BRASIL. Programa Segundo Tempo Padrão: diretrizes e orientações para estabelecimento de Parcerias. Brasília: Ministério do Esporte, 2009.

CORREIA, Marcos Miranda. Projetos sociais em educação física, esporte e lazer: reflexões preliminares para uma gestão social. Revista Brasileira de Ciências do Esporte, v. 29, n. 3, p. 91105, maio 2008.

FARAH, Marta Ferreira Santos. Sete décadas de políticas sociais no Brasil. Revista do Serviço Público, p. 111-122, 2007. Edição especial 70 anos.

FILGUEIRA, Júlio César Munzú; OLIVEIRA, Amauri Aparecido Bássoli; PERIM, Gianna Lepre. Apresentação. In: OLIVEIRA, Amauri Aparecido Bássoli; PERIM, Gianna Lepre (Org.). Fundamentos pedagógicos para o Programa Segundo Tempo: da reflexão à prática. Maringá: Eduem, 2009. p. 9-18.

GASQUE, Kelley Cristina Gonçalves Dias; COSTA, Sely Maria Souza. Comportamento dos professores da educação básica na busca da informação para formação continuada. Ciência da Informação, v. 32, n. 3, p. 54-61, 2003.

GATTI, Bernardete Angelina. Análise das políticas públicas para formação continuada no Brasil, na última década. Revista Brasileira de Educação, v. 13, n. 37, p. 57-70, jan./abr. 2008.

GONZÁLEZ, Fernando Jaime et al. Nas pegadas do esporte educacional. In: MARINHO, Alcyane; NASCIMENTO, Juarez Vieira; OLIVEIRA, Amauri Aparecido Bássoli (Org.). Legados do esporte brasileiro. Florianópolis: Editora da UDESC, 2014. p.35-43.

HIRAMA, Leopoldo Katsuki; MONTAGNER, Paulo César. Algo para além de tirar da rua: o ensino do esporte em projeto socioeducativo. Revista Brasileira de Ciências do Esporte, v. 34, n. 1, p. 149164, jan./mar. 2012.

KRAVCHYCHYN, Claudio. Projetos e programas sociais esportivos no Brasil: histórico, estado da arte e contribuições do Programa Segundo Tempo. 177 f. 2014. Tese (Doutorado em Educação Física). Universidade Estadual de Maringá, Maringá, 2014.

KRÜGER, Leonardo Germano; KRUG, Hugo Norberto. Licenciatura em Educação Física: concepções a partir da vivência experienciada dos professores do ensino superior em seu percurso formativo.

Movimento, v. 15, n. 1, p. 51-70, 2009.

LAZZARI, André; THOMASSIM, Luís Eduardo Cunha; STIGGER, Marco Paulo. A socialização de crianças e adolescentes no contexto de um projeto social de tênis. Caderno de Educação Física, v. 9, n. 16, p. 51-64, 1. sem. 2010.

MACHADO, Gisele Viola; PAES, Roberto Rodrigues; GALATTI, Larissa Rafaela; RIBEIRO, Sheila Cristina. Pedagogia do esporte e autonomia: um estudo em projeto social de educação não formal.

Pensar a Prática, v. 14, n. 3, p. 1-21, set./dez. 2011. 
MELLO, André Silva; FERREIRA NETO, Amarílio; VOTRE, Sebastião Josué. Intervenção da educação física em projetos sociais: uma experiência de cidadania e esporte em Vila Velha (ES). Revista Brasileira de Ciências do Esporte, v. 31, n. 1, p. 75-91, set. 2009.

MELO, Victor Andrade. Projetos sociais de esporte e lazer: reflexões, inquietações, sugestões. Quaderns d'Animació i Educació Social, n. 7, p. 1-24, jan. 2008.

MONTEIRO, Victor Hugo Lima. Projeto Segundo Tempo: o Fanzine e a leitura do esporte em bairros violentos. Conexões, v. 8, n. 3, p. 10-15, set./dez. 2010.

MOREIRA, Evando Carlos. A proposta pedagógica do Programa Segundo Tempo na Visão dos Educadores: equipe colaboradora. In: GOELLNER, Silvana Vilodre; SOARES, Luciane Silveira; CARVALHO, Marco Antônio Ávila (Org.). Programa Segundo Tempo: memória, experiências, avaliação e perspectivas no Encontro das Equipes Colaboradoras (São Paulo-2010). Maringá: Eduem, 2012. p. 168-181.

OLIVEIRA, Amauri Aparecido Bássoli; KRAVCHYCHYN, Claudio. The pedagogic monitoring and managerial of the Second Journey Program from the cooperate teams sight. FIEP Bulletin, n. 81, p. 404-407, 2011. Edição especial.

OLIVEIRA, Amauri Aparecido Bássoli et al. Planejamento do Programa Segundo Tempo: a intenção é compartilhar conhecimentos, saberes e mudar o jogo. In:

OLIVEIRA, Amauri Aparecido Bássoli; PERIM, Gianna Lepre (Org.). Fundamentos pedagógicos para o Programa Segundo Tempo: da reflexão à prática. Maringá: Eduem, 2009. p. 208-237.

OLIVEIRA, Amauri Aparecido Bássoli; PERIM, Gianna Lepre (Org.). Fundamentos Pedagógicos do Programa Segundo Tempo. Maringá: Eduem, 2008.

OLIVEIRA, Amauri Aparecido Bássoli; PERIM, Gianna Lepre (org.). Fundamentos Pedagógicos do Programa Segundo Tempo: da reflexão à prática. Maringá: Eduem, 2009.

RODRIGUES, Heitor Andrade; DARIDO, Suraya Cristina; PAES, Roberto Rodrigues. O esporte coletivo no contexto dos projetos esportivos de inclusão social: contribuições a partir do referencial técnico-tático e sócio-educativo. Pensar a Prática, v. 16, n. 2, p. 320-339, abr.jun. 2013.

RODRIGUES, Heitor Andrade et al. O Programa Segundo Tempo e seu processo de capacitação: análise e proposições. Motrivivência, v. 24, n. 38, p. 108-122, jun. 2012.

ROSÁRIO, Luís Fernando Rocha; DARIDO, Suraya Cristina. A sistematização dos conteúdos da educação física na escola: a perspectiva dos professores experientes. Motriz, v. 11, n. 3, p. 167-178, set./dez. 2005.

SILVA, Everson Melquiades Araújo; ARAÚJO, Clarissa Martins. Reflexão em Paulo Freire: uma contribuição para a formação continuada de professores. In: COLÓQUIO INTERNACIONAL PAULO FREIRE, 5, Recife, 2005. Anais... Disponível em: <http:// 189.28.128.100/nutricao/docs/Enpacs/ pesquisaArtigos/reflexao em paulo freire 2005.pdf >. Acesso em: 3 ago. 2016.

SILVEIRA, Juliano. Considerações sobre o esporte e o lazer: entre direitos sociais e projetos sociais. Licere, v. 16, n. 1, p. 1-22, mar. 2013.

SOUZA, Doralice Lange; VIALICH, Andrea Leal; EIRAS, Suélen Barbosa; MEZZADRI, Fernando Marinho. Determinantes para a implementação de um projeto social. Motriz, v. 16, n. 3, p. 689-700, jul./ set. 2010.

SOUZA, Edison Roberto et al. Projeto de educação pelo esporte: estudo de caso sobre a contribuição do Brinca Mané na formação discente. Pensar a Prática, v. 14, n. 1, p. 1-12, jan./abr. 2011.

SOUZA, Edison Roberto et al. Análise do educador sobre implantação de cartões de apoio pedagógico no Programa Segundo Tempo. Revista Mackenzie de Educação Física e Esporte, v. 12, n. 1, p. 41-52, 2013. 
STAREPRAVO, Fernando Augusto et al. As Equipes Colaboradoras do Programa Segundo Tempo e suas contribuições para o desenvolvimento de uma política de esporte educacional. Motrivivência, v. 24, n. 38, p. 129-141, jun. 2012.

TEIXEIRA, Fabiane Castilho. Diretrizes pedagógicas do Programa Segundo Tempo e suas relações com as ações cotidianas dos núcleos. 144 f. 2012. Dissertação (Mestrado em Educação Física) - Universidade Estadual de Maringá, Maringá, 2012.

TUBINO, Manoel José Gomes. Estudos brasileiros sobre esporte: ênfase no esporte-educação. Maringá: Eduem, 2010.

VIANNA, José Antonio; LOVISOLO, Hugo Rodolfo. Projetos de inclusão social através do esporte: notas sobre a avaliação. Movimento, v. 15, n. 3, p. 145-162, jul./set. 2009.

YIN, Robert K. Estudo de caso: planejamento e métodos. Porto Alegre: Bookman, 2005.

ZALUAR, Alba. Cidadãos não vão ao paraíso. São Paulo: Escuta, 1994. 
